\title{
Rescue of Dopamine Transporter Function in Hypoinsulinemic Rats by a $\mathrm{D}_{2}$ Receptor-ERK-Dependent Mechanism
}

\author{
W. Anthony Owens, ${ }^{1 \star}$ Jason M. Williams, ${ }^{3,6,7 \star}$ Christine Saunders, ${ }^{4,6}$ Malcolm J. Avison, ${ }^{4,5,7 \#}$ Aurelio Galli, ${ }^{3,6^{\#}}$ \\ and Lynette C. Daws ${ }^{1,2}{ }^{\#}$ \\ Departments of ${ }^{1}$ Physiology and ${ }^{2}$ Pharmacology, The University of Texas Health Science Center, San Antonio, Texas 78229, and Departments of ${ }^{3}$ Molecular \\ Physiology and Biophysics, ${ }^{4}$ Pharmacology, and ${ }^{5}$ Radiology and Radiological Sciences, ${ }^{6}$ Center for Molecular Neuroscience, and ${ }^{7}$ Institute of Imaging \\ Science, Vanderbilt University Medical Center, Nashville, Tennessee 37232
}

The dopamine (DA) transporter (DAT) is a major target for abused drugs and a key regulator of extracellular DA. A rapidly growing literature implicates insulin as an important regulator of DAT function. We showed previously that amphetamine (AMPH)-evoked DA release is markedly impaired in rats depleted of insulin with the diabetogenic agent streptozotocin (STZ). Similarly, functional magnetic resonance imaging experiments revealed that the blood oxygenation level-dependent signal following acute AMPH administration in STZ-treated rats is reduced. Here, we report that these deficits are restored by repeated, systemic administration of AMPH (1.78 $\mathrm{mg} / \mathrm{kg}$, every other day for $8 \mathrm{~d}$ ). AMPH stimulates $\mathrm{DA}_{2}$ receptors indirectly by increasing extracellular $\mathrm{DA}$. Supporting a role for $\mathrm{D}_{2}$ receptors in mediating this "rescue," the effect was completely blocked by pre-treatment of STZ-treated rats with the $\mathrm{D}_{2}$ receptor antagonist raclopride before systemic AMPH. $\mathrm{D}_{2}$ receptors regulate DAT cell surface expression through ERK1/2 signaling. In ex vivo striatal preparations, repeated AMPH injections increased immunoreactivity of phosphorylated ERK1/2 (p-ERK1/2) in STZ-treated but not control rats. These data suggest that repeated exposure to AMPH can rescue, by activating $\mathrm{D}_{2}$ receptors and p-ERK signaling, deficits in DAT function that result from hypoinsulinemia. Our data confirm the idea that disorders influencing insulin levels and/or signaling, such as diabetes and anorexia, can degrade DAT function and that insulin-independent pathways are present that may be exploited as potential therapeutic targets to restore normal DAT function.

\section{Introduction}

The dopamine (DA) transporter (DAT) is the primary highaffinity uptake mechanism for DA after it is released into the extracellular milieu. As such, it exerts tight control over the strength and duration of DA neurotransmission. DAT is a primary target for many abused drugs, prominent among them, amphetamine (AMPH). Not surprisingly then, a major research focus has been geared toward understanding mechanisms regulating DAT activity and the action of AMPH. Emerging as an important modulator of DAT activity is insulin signaling, via phosphotidylinositol 3-kinase (PI3K) and Akt (Garcia et al., 2005; Wei et al., 2007; Williams et al., 2007). Inhibition of PI3K signaling reduces cell surface expression of DAT, and DA uptake is reduced as a result (Williams et al., 2007). Using rodent models,

\footnotetext{
Received July 21, 2011; revised Jan. 4, 2012; accepted Jan. 4, 2012.

Author contributions: J.M.., C.S., M.J.A., A.G., and L.C.D. designed research; W.A.O., J.M.W., and C.S. performed research; W.A.O., J.M.W., C.S., and L.C.D. analyzed data; J.M.W., C.S., M.J.A., A.G., and L.C.D. wrote the paper.

This study was supported by NIH Grants DA018992 (L.C.D.), DK08571 (A.G.), and DA014684 (A.G., L.C.D.).

${ }^{*}$ W.A.O. and J.M.W. contributed equally to this work.

\#M.J.A., A.G., and L.C.D contributed equally to this work.

Correspondence should be addressed to Dr. Lynette C. Daws, Department of Physiology, University of Texas

Health Science Center at San Antonio, 7703 Floyd Curl Drive, MC 7756, San Antonio, TX 79229-3900. E-mail: daws@uthscsa.edu.

DOI:10.1523/JNEUROSCI.3759-11.2012

Copyright $\odot 2012$ the authors $\quad 0270-6474 / 12 / 322637-11 \$ 15.00 / 0$
}

we and others found that under conditions of low circulating insulin, such as occurs following fasting or food restriction, as well as in disease states, such as diabetes, clearance of DA is dramatically reduced (Patterson et al., 1998; Owens et al., 2005; Sevak et al., 2007a). Likewise, in rats treated with the diabetogenic agent streptozotocin (STZ), both the magnitude of AMPH stimulated release of endogenous DA in striatum and its rate of clearance are markedly reduced (Williams et al., 2007). These effects of STZ on the kinetics of AMPH-evoked DA release and uptake were correlated with a striking decrease in the ability of AMPH to increase the blood oxygen level-dependent (BOLD) signal in striatum, measured by functional magnetic resonance imaging (fMRI) (Williams et al., 2007).

Interestingly, we found that the sluggish clearance of exogenously applied DA from striatum in hypoinsulinemic rats could be completely restored to normal DA clearance rate by administration of four AMPH injections given once every other day for $8 \mathrm{~d}$, a dosing regimen that establishes conditioned place preference for AMPH (Sevak et al., 2007a). However, the mechanism through which this occurs remains unknown. AMPH, by stimulating DA release, acts as an indirect $\mathrm{D}_{2}$ receptor agonist. Consistent with $\mathrm{D}_{2}$ receptor involvement in mediating the effect of repeated AMPH to restore DA clearance in hypoinsulinemic rats, the $D_{2} / D_{3}$ receptor antagonist raclopride (RAC) given before AMPH completely blocked the ability of AMPH to restore DA 
clearance rate (Sevak et al., 2007a). $D_{2} / D_{3}$ receptor stimulation causes a rapid increase in DAT cell surface expression that is ERK1/2-dependent and enhances substrate clearance (Bolan et al., 2007; Lee et al., 2007; Zapata et al., 2007). Thus, stimulation of $\mathrm{D}_{2}$ receptors following repeated AMPH administration may promote DAT activity in the plasma membrane and act to reverse the effect of hypoinsulinemia to slow DA clearance and blunt the effect of a single acute intrastriatal injection of AMPH to stimulate DA release. Here we show that repeated systemic AMPH restores the ability of an acute injection of AMPH to cause DA efflux, inhibit DA clearance, and induce a BOLD response in hypoinsulinemic rats. We provide evidence supporting a role for ERK1/2 signaling via $\mathrm{D}_{2}$ receptors in mediating these effects of repeated $\mathrm{AMPH}$ administration to restore DAT function.

\section{Materials and Methods}

Animals. Male Sprague Dawley rats (275-350 g; Harlan) were used for all experiments. Rats were rendered hypoinsulinemic by a single injection of STZ [ $65 \mathrm{mg} / \mathrm{kg}$ into the tail vein for fMRI studies; $65 \mathrm{mg} / \mathrm{kg}$, i.p., for ERK activity studies; $50 \mathrm{mg} / \mathrm{kg}$, i.p., for high-speed in vivo chronoamperometry (HSCA) studies]. These doses and routes of administration produced similar increases in blood glucose. STZ is an antibiotic that destroys the insulin-secreting $\beta$ cells of the pancreas (Szkudelski, 2001) and has been used to induce chronic hypoinsulinemia in rats by our laboratories (Owens et al., 2005; Williams et al., 2007) and others (Carr et al., 2000). STZ (Sigma-Aldrich) was freshly dissolved in ice-cold $100 \mathrm{~mm}$ citrate saline (SAL; $\mathrm{pH} 4.5$ ) for all studies. For in vivo studies examining AMPH-stimulated BOLD responses using fMRI and ex vivo studies measuring ERK activity, rats received one of two treatment regimens 1 week following an injection of STZ or saline. These regimes comprised two injections every other day for $8 \mathrm{~d}$. The two injections were either salinesaline or saline-AMPH $(1.78 \mathrm{mg} / \mathrm{kg}$, i.p.). For in vivo studies measuring AMPH-stimulated DA release using HSCA, two additional treatment groups were included: RAC-saline $(0.056 \mathrm{mg} / \mathrm{kg}$, i.p., RAC) or RACAMPH $(0.056$ and $1.78 \mathrm{mg} / \mathrm{kg}$, i.p., respectively). In all studies, the first injection was given $30 \mathrm{~min}$ before the second. Two to $4 \mathrm{~d}$ after the last injection (i.e., when these systemically administered drugs are metabolized) (Sevak et al., 2007a), rats were prepared for (1) fMRI analysis of AMPH stimulated BOLD response in striatum, (2) ex vivo analysis of striatal ERK activity, or (3) in vivo HSCA recordings of striatal DA efflux induced by locally applied AMPH. The experimental timeline is shown in Figure 1.

A dose of $1.78 \mathrm{mg} / \mathrm{kg}$ AMPH was chosen because we established that this normalizes clearance of exogenously applied DA in striatum and AMPH-induced locomotion in STZ-treated rats (Owens et al., 2005). A dose of $0.056 \mathrm{mg} / \mathrm{kg}$ raclopride was selected based on our studies showing that $0.056 \mathrm{mg} / \mathrm{kg}$ is the smallest dose of raclopride that produces a significant rightward shift in the dose-effect curve of the $\mathrm{D}_{2} / \mathrm{D}_{3}$ receptor agonist quinpirole to elicit yawning (Sevak et al., 2007b) and effectively blocked normalization of clearance of exogenously applied DA by repeated AMPH in STZ-treated rats (Sevak et al., 2007a).

In a separate study to investigate the effect of increasing insulin, rats were surgically implanted with a subcutaneous pellet that delivered $2 \mathrm{U}$ of insulin per day (Linplant) according to methods described by Sevak et al., (2007b). Drinking water was supplemented for the first $4 \mathrm{~d}$ with $10 \%$ glucose to avoid severe hypoglycemia. Control animals received a sham surgery and insertion of a palmitic acid implant and also received $10 \%$ glucose in their drinking water for the first $4 \mathrm{~d}$. HSCA experiments were performed $7 \mathrm{~d}$ after the surgeries.

Blood glucose was measured with a glucometer (Advantage AccuChek; Roche Diagnostics) before STZ or saline injection and just before an experiment. Animals were considered hypoinsulinemic when their glucose levels exceeded $300 \mathrm{mg} / \mathrm{dl}$. All procedures were approved by the University of Texas Health Science Center at San Antonio and Vanderbilt University Medical Center Institutional Animal Care and Use Committees and were conducted according to the National Institutes of Health Guide for the Care and Use of Laboratory Animals.

$f M R I$. Animals were prepared for fMRI as described previously (Williams et al., 2007; 2010). Before scanning, animals were catheterized and tracheotomized under $2 \%$ isoflurane. After surgery and before fMRI, animals were given pancuronium bromide $(2 \mathrm{mg} / \mathrm{kg} / \mathrm{h}$, i.p.; Sigma), isoflurane was decreased to $0.8 \%$ in $33 \%$ oxygen $/ 67 \%$ nitrous oxide and the ventilator was adjusted to produce constant respiration of $50-52$ breaths per minute, a rate ideal for stable physiological conditions. End-tidal carbon dioxide $\left(\mathrm{EtCO}_{2}\right)$, an indirect measure of arterial $\mathrm{pCO}_{2}$, was continuously monitored via a capnograph (SurgiVet). Physiologic temperature was verified by rectal probe and maintained by a heating unit with extension hose placed inside the magnet bore. Heart rate was monitored via subdermal electrocardiograph electrodes implanted into the forepaws. Physiologic data were collected and analyzed using the SAM-PC MRI-compatible monitoring and gating system (SA Instruments). Under these conditions, no significant differences in pre-AMPH baseline $\mathrm{EtCO}_{2}$ were seen across the three treatment groups $(\mathrm{mm} \mathrm{Hg}): 25.5 \pm 1.59$ (saline/4×AMPH/AMPH, $n=8), 26.9 \pm 1.70(\mathrm{STZ} / 4 \times \mathrm{AMPH} / \mathrm{AMPH}$, $n=7)$, and $23.6 \pm 1.85$ (STZ/4 $\times$ saline/AMPH, $n=7$; one-way ANOVA; $\left.F_{(2,19)}=0.893 ; p=0.426\right)$.

Animals were moved to a Plexiglas stereotaxic frame in which the head was immobilized with adjustable ear and incisor bars. Attached to the frame was a $2 \mathrm{~cm}$ radio frequency (RF) surface coil (Varian Instruments) lowered to within $1 \mathrm{~mm}$ above the scalp. Microbore tubing was attached to intraperitoneal catheters to allow drug administration within the magnet during fMRI. Functional images were acquired at 9.4 Tesla using a multislice gradient echo sequence with the following parameters: TR, 220 $\mathrm{ms}$; TE, $12 \mathrm{~ms}$; nominal flip angle, $20^{\circ}$; number of excitations, 2; FOV, $30 \times 30 \mathrm{~mm}$; matrix, $64 \times 64 ; 9 \times 1 \mathrm{~mm}$ contiguous slices. Functional scans consisted of 72 image volumes serially acquired without interruption over a predrug baseline period, a $\sim 30 \mathrm{~s}$ bolus injection of AMPH $(1.78 \mathrm{mg} / \mathrm{kg}$, i.p.), and a post-AMPH period. Acquisition time was $\sim 30$ min. Functional data from all subjects were registered to a common template and interpolated to high-resolution anatomic images having the same slice prescription in AFNI (version 2008_02_01_1144; http://afni.nimh.nih.gov/afni). MR signal outside the brain was masked, and registered data were temporally smoothed with a three-point Hamming filter and converted to a percent BOLD signal change relative to the pre-AMPH baseline period $\left(\Delta S / S_{0}\right.$, in percent) on a voxelwise basis. Data were linearly detrended to correct for baseline signal drift and underwent additional masking wherein voxels having a temporal signal-to-noise ratio (SNR) $<20 \%$ of the peak SNR were silenced. This latter step eliminated signal artifacts in voxels having low SNR within extreme ventral portions of the brain most distant from the RF surface coil. To compare regional differences in BOLD activation across treatment conditions, the postinjection $\Delta S / S_{0}$ (mean of the 36 images following AMPH) from each subject was group averaged, and the group activation map, thresholded 
at mean $\Delta S / S_{0}>1 \%$ was overlaid on the high-resolution anatomic image. Region-of-interest (ROI) analyses were conducted over the anterior and posterior caudate-putamen in reference to a standard rat brain atlas (Paxinos and Watson, 1998). MR signal changes $\left(\Delta S / S_{0}\right.$, in percent) were averaged across left and right ROIs, integrated, and analyzed by one-way ANOVA followed by a Bonferroni's multiple comparison test in Prism (version 5.0a; GraphPad Software).

Immunoblotting of synaptosomal phospho-ERK1/2 after in vivo AMPH administration or after incubation with insulin in vitro. Phosphorylated ERK1/2 (p-ERK1/2) was assayed according the method of Shi and McGinty (2006). Rats, treated in the same way as for fMRI studies, were killed and striatal synaptosomes prepared. In separate experiments, synaptosomes prepared from drug-naive control rats were incubated with either 1 or $10 \mathrm{~nm}$ insulin for 10 or $5 \mathrm{~min}$, respectively. Protein equivalents of synaptosomal preparations were subjected to $10 \%$ SDS-PAGE and then probed with anti pERK1/2-p44/42 antibody (1:5000; Promega). The membranes were then incubated with goat anti-rabbit HRP-conjugated secondary antibody (1:1000; Millipore). The same membranes were the stripped and reprobed for total ERK1/2 (anti-ERK1/2, 1:5000; Promega) for loading control. After chemiluminescent visualization on Hyperfilm ECL film, protein band densities were quantified and analyzed using Scion Image. To assess the change in p-ERK1/2 as a result of multiple AMPH administrations, every lane of $\mathrm{p}$-ERK1/2 was normalized to its respective total ERK1/2 lane, and the change from percentage of control reflects this normalized ratio.

HSCA. HSCA was conducted using the FAST-12 system (Quanteon) as described previously (Callaghan et al., 2005; Williams et al., 2007). Recording electrode/micropipette assemblies were constructed using a single carbon-fiber (30 $\mu$ m diameter; Specialty Materials), which was sealed inside fused silica tubing (Schott). The exposed tip of the carbon fiber $(150 \mu \mathrm{m}$ in length) was coated with $5 \%$ Nafion (Aldrich Chemical; three to four coats baked at $200^{\circ} \mathrm{C}$ for $5 \mathrm{~min}$ per coat) to provide a 1000 -fold selectivity of DA over its metabolite dihydroxyphenylacetic acid. Under these conditions, the current generated by cumulative $0.5 \mu \mathrm{M}$ additions of DA $(0.5-10 \mu \mathrm{M})$ during in vitro calibration in $100 \mathrm{~mm} \mathrm{PBS}, \mathrm{pH} 7.4$, was linear $\left(r^{2}<0.99\right)$.

Animals were anesthetized with an injection of urethane $(850 \mathrm{mg} / \mathrm{kg}$, i.p.) and $\alpha$-chloralose ( $85 \mathrm{mg} / \mathrm{kg}$, i.p.) mixture, fitted with an endotracheal tube to facilitate breathing, and placed into a stereotaxic frame (David Kopf Instruments). To locally deliver test compounds (described below) close to the recording site, a glass multibarrel micropipette (FHC) was positioned adjacent to the microelectrode using sticky wax. The center-to-center distance between the microelectrode and the micropipette ejector was $300 \mu \mathrm{m}$. Experiments in Figures 4 and 5 used a multibarrel configuration in which barrels contained AMPH $(400 \mu \mathrm{M}), \mathrm{RAC}$ (400 $\mu \mathrm{M}$; Sigma), or vehicle [artificial CSF (ACSF)]. Experiments in Figure 6 used barrels filled with DA $(200 \mu \mathrm{M})$, the ERK1/2 inhibitor SL327 ( $2 \mathrm{~mm}$ ), or vehicle (ACSF with 10\% DMSO) and in the final series of experiments (see Fig. 8), barrels were filled with DA $(200 \mu \mathrm{M})$. The electrode/micropipette assembly was lowered into the striatum at the following coordinates (in mm from bregma) (Paxinos and Watson, 1998): AP, +1.5 ; $\mathrm{ML}, \pm 2.2$; DV,-3.5 to -5.5 . The application of drug solutions was accomplished using a Picospritzer II (General Valve Corporation) in an ejection volume of $125 \mathrm{nl}$ (5-25 psi for $0.25-3 \mathrm{~s}$ ). After ejection of test agents, there is an estimated 10- to 200 -fold dilution caused by diffusion through the extracellular matrix to reach a concentration of 2-40 $\mu \mathrm{M}$ (AMPH and RAC) at the recording electrode (Callaghan et al., 2005), concentrations equivalent to those found in brain after systemic administration of AMPH (Clausing et al., 1995). To record the efflux and clearance of DA at the active electrode, oxidation potentials (consisting of $100 \mathrm{~ms}$ pulses of $550 \mathrm{mV}$, each separated by a $0.9 \mathrm{~s}$ interval during which the resting potential was maintained at $0 \mathrm{mV}$ ) were applied with respect to an $\mathrm{Ag} / \mathrm{AgCl}$ reference electrode implanted into the contralateral superficial cortex. Oxidation and reduction currents were digitally integrated during the last $80 \mathrm{~ms}$ of each $100 \mathrm{~ms}$ voltage pulse. For each recording session, DA was identified by its reduction/oxidation current ratio: 0.50 to 0.80 .

At the conclusion of each experiment, an electrolytic lesion was made to mark the placement of the recording electrode tip. Rats were then decapitated while still anesthetized, and their brains were removed, frozen on dry ice, and stored at $-80^{\circ} \mathrm{C}$ until sectioned $(20 \mu \mathrm{m})$ for histo- logical verification of electrode location within the striatum. HSCA data were analyzed with GraphPad Prism using three signal parameters (see Fig. $4 A-D$ ): (1) the DA efflux rate (in nanomolar per second), which is the change in DA oxidation current evoked by AMPH application as a function of time of the ascending limb of the signal; (2) the maximal signal amplitude of the released DA (in micromolar); and (3) the DA clearance rate (in nanomolar per second), defined as the slope of the linear portion of the current decay curve, i.e., from $20-60 \%$ of maximal signal amplitude.

Statistical analyses. All treatment and drug effects were analyzed using ANOVA followed by Bonferroni's post hoc tests or $t$ tests. All data are presented as mean \pm SEM.

\section{Results}

\section{Repeated intraperitoneal injections of AMPH rescues} AMPH-induced striatal BOLD response in STZ-treated rats We found previously that the AMPH-induced BOLD response is significantly diminished after depletion of insulin with STZ (Williams et al., 2007). In the present study, STZ-treated rats or untreated (euinsulinemic) control rats were challenged acutely with AMPH (1.78 mg/kg, i.p.) in the MR scanner $4 \mathrm{~d}$ after receiving the last of four injections (every other day) of AMPH $(1.78 \mathrm{mg} / \mathrm{kg}$, i.p.) or saline vehicle, i.e., $17 \mathrm{~d}$ after STZ injection. Our results confirm and extend our previous findings: compared with control rats (Fig. 2A), STZ-treated rats receiving intraperitoneal saline injections every other day for $8 \mathrm{~d}$ showed significant blunting of the AMPH-evoked BOLD signal response across multiple brain areas including neocortex, striatum, and thalamus (Fig. $2 B$ ). In sharp contrast, repeated AMPH injections restored the patterns of BOLD signal responses in STZ-treated rats to those observed in control rats (Fig. 2C). Summary data from the DATand insulin receptor (IR)-enriched striatum are shown in Figure $2 D-F$. ROI time-series data from the anterior and posterior caudate-putamen (Fig. 2D) were integrated $15 \mathrm{~min}$ before (baseline) and after AMPH injection (Fig. 2E). Relative to their respective preinjection baselines, AMPH-stimulated significant increases in striatal BOLD signal in both untreated control rats and in STZtreated rats $\left(F_{(5,44)}=6.984 ; p<0.0001\right)$. In contrast to the AMPH-naive STZ-treated rats, STZ-treated rats with a history of repeated AMPH injections showed a BOLD response to acute AMPH challenge that was not significantly different from control rats. Repeated AMPH injections in control rats did not alter the BOLD response to subsequent AMPH challenge and was comparable to the AMPH-stimulated BOLD response we reported in AMPH-naive control rats (Williams et al., 2007). Acute injection of saline did not evoke any significant change in the striatal BOLD response regardless of prior treatment (data not shown) (but see Williams et al., 2007).

\section{Repeated intraperitoneal injections of AMPH increase striatal ERK1/2 activity}

AMPH acts directly at DAT and indirectly by increasing extracellular DA concentration at DA receptors. We showed previously that injection of STZ-treated rats with AMPH $(1.78 \mathrm{mg} / \mathrm{kg})$ every other day for $8 \mathrm{~d}$ restored normal clearance of exogenously applied DA and the ability of AMPH to induce locomotion (Owens et al., 2005; Sevak et al., 2007a). This effect of repeated intraperitoneal AMPH injections was blocked by pretreatment with the $\mathrm{D}_{2} / \mathrm{D}_{3}$ receptor antagonist $\mathrm{RAC}(0.056 \mathrm{mg} / \mathrm{kg})$ (Sevak et al., 2007a). We have also shown that ERK1/2 regulates DAT function and cell surface expression and that activation of ERK1/2 increases transport capacity (Morón et al., 2003). Importantly, $\mathrm{D}_{2} / \mathrm{D}_{3}$ receptors signal to activate ERK1/2 (Bolan et al., 2007; Lee et al., 2007; Zapata et al., 2007). Therefore, we hypothesized that 
(fMRI)

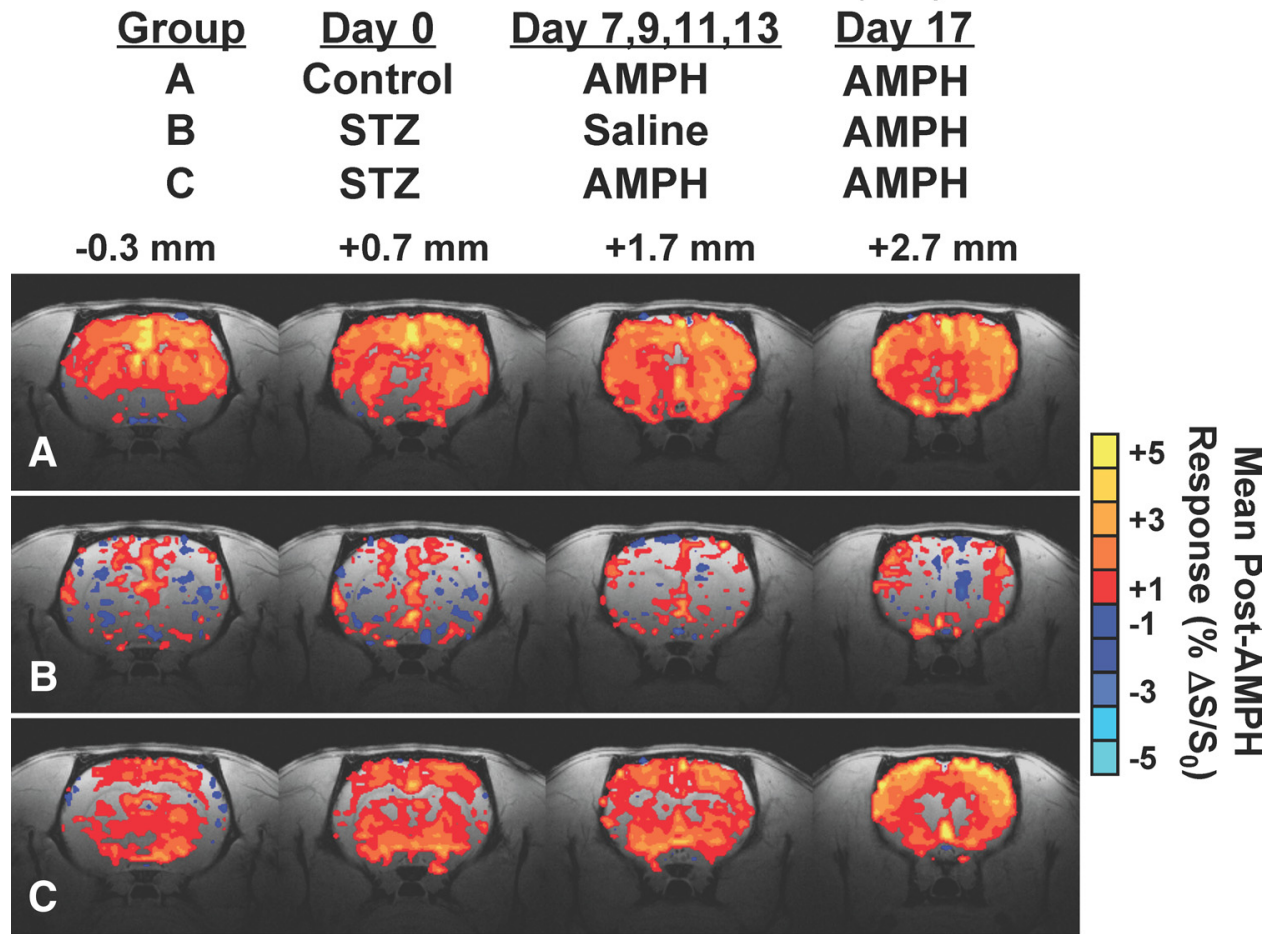
D - Control / 4x AMPH / AMPH (8)
- STZ / 4x AMPH / AMPH (8)
$\sim$ STZ / 4x Saline / AMPH (9)

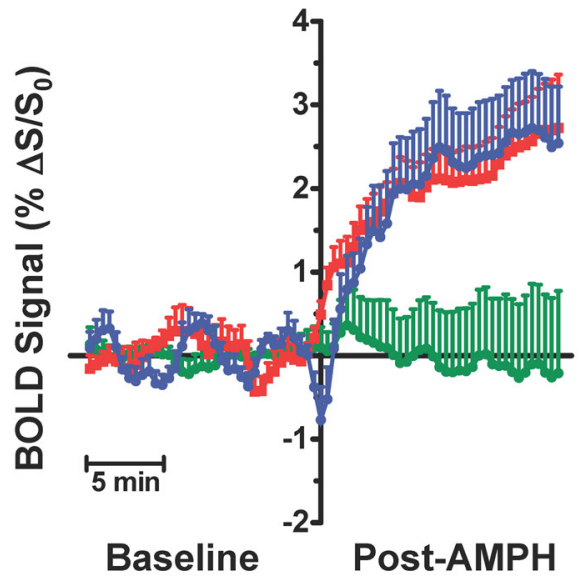

E

- Control / 4x AMPH / AMPH (8)

- STZ / 4x AMPH / AMPH (8)

- STZ / 4x Saline / AMPH (9)

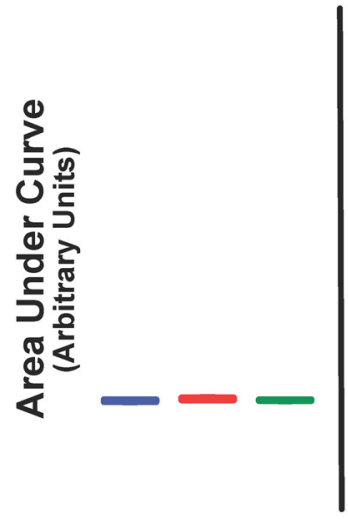

Baseline

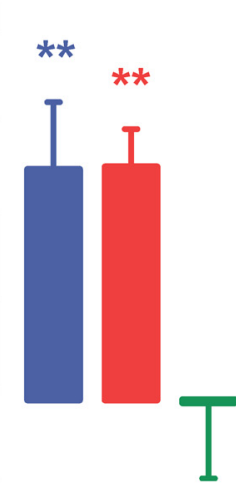

Post-AMPH

F

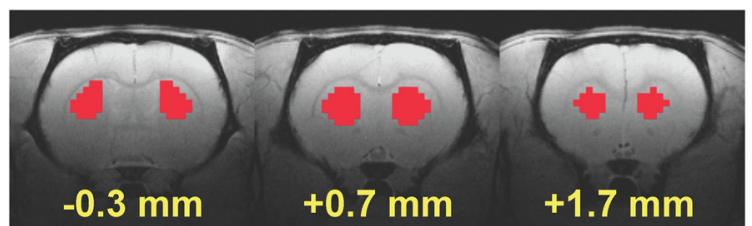

Figure 2. Repeated AMPH rescues the AMPH-induced striatal BOLD response in STZ-treated rats. $A-C, B O L D$ activation maps were overlaid on high-resolution anatomic templates to depict regional mean postinjection BOLD signal changes $\left(\triangle S / S_{0}\right.$, in percent) in response to AMPH challenge $(1.78 \mathrm{mg} / \mathrm{ml}$, i.p.) for untreated (euinsulinemic) control rats that received repeated AMPH injections $(\boldsymbol{A})$, STZ-treated (hypoinsulinemic) rats that received repeated saline injection $(\boldsymbol{B})$, and STZ-treated rats with a history of repeated AMPH injections $(\boldsymbol{C}) . \boldsymbol{D}-\boldsymbol{F}$, ROI time series within the DAT and IR-rich striatum for all three treatment groups $4 \mathrm{~d}$ after the last saline or AMPH injection, i.e., $17 \mathrm{~d}$ after STZ. D, Time-series data from the caudate-putamen of each treatment group showing the 15 min post-AMPH response after the 15 min baseline period. E, Comparisons of the area under curve for the pre-AMPH and post-AMPH periods across the three treatment groups in the study reveal significant and equivalent increases in BOLD activation in dorsal striatum after AMPH in both euinsulinemic control and STZ-treated rats with a history of repeated AMPH injection. In contrast, STZ-treated rats receiving AMPH for the first time show a dramatically blunted BOLD signal change. ${ }^{* *} p<0.01$ versus baseline (one-way ANOVA with Bonferroni's multiple comparison test; $n=$ 8-9 per group). $\boldsymbol{F}$, Position of right and left ROIs (red voxels) drawn in the anterior and posterior caudate-putamen. Stereotaxic coordinates indicate the approximate rostrocaudal distance from bregma of the multislice images used in this study (Paxinos and Watson, 1998). 
A

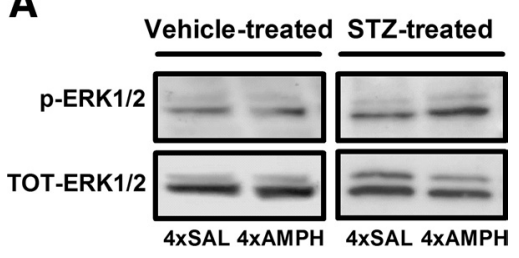

B

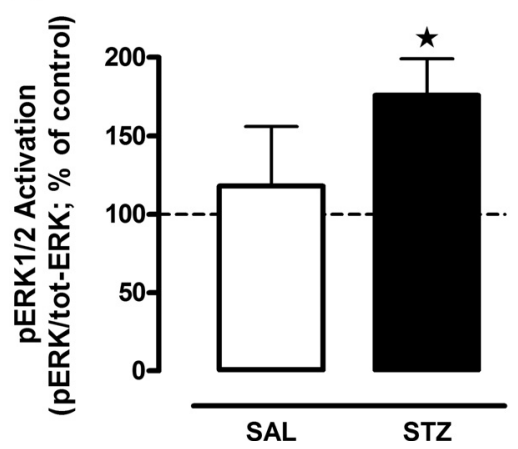

Figure 3. Repeated intraperitoneal injections of AMPH increase striatal ERK1/2 activity in diabetic rats. $\boldsymbol{A}$, Representative immunoblots of $\mathrm{p}$-ERK1/2 (top) and total ERK1/2 (bottom) obtained from striatal synaptosomes from saline- or STZ-treated rats, given either repeated vehicle ( $4 \times$ saline) or repeated AMPH injections $(4 \times \mathrm{AMPH})$ according to the timeline in Figure 1. $\boldsymbol{B}$, Summary data showing $\mathrm{p}$-ERK1/2 normalized to total ERK1/2 and expressed as a percentage of respective controls ( $4 \times$ saline). Repeated AMPH injections produced a significant increase in $p$-ERK1/2 only in STZ-treated rats. ${ }^{*} p<0.05$ (Student's $t$ test), STZ treated $(n=7)$ versus vehicle treated $(n=3)$.

restoration of the AMPH-stimulated BOLD response in STZtreated rats is mediated by $\mathrm{D}_{2}$ receptor activation of ERK1/2 signaling. Figure 3 shows immunoblots for p-ERK1/2 and total ERK1/2 obtained from striatal synaptosomes of saline- or STZtreated rats $2 \mathrm{~d}$ after receiving the last injection of the repeated saline or repeated AMPH regimen (four injections every other day for $8 \mathrm{~d}$ ). Hypoinsulinemia was confirmed in all STZ-treated rats. As seen in Figure 3, repeated AMPH administration in STZtreated rats increased p-ERK1/2 to $176 \pm 23 \%$ of control $(n=7$; $p<0.05$ by Student's $t$ test). Repeated AMPH administration did not, however, alter ERK1/2 activity in control (euinsulinemic) rats ( $118 \pm 38 \%$ of control; $n=3 ; p>0.05)$. We also investigated the effect of a single acute injection of AMPH $(1.78 \mathrm{mg} / \mathrm{kg}$, i.p.) on ERK1/2 activity measured $2 \mathrm{~d}$ later. As expected, there was no effect of the single AMPH injection on ERK1/2 activity in control (euinsulinemic) rats $(82 \pm 9 \% ; n=10)$. Interestingly, there was a trend for a single injection of AMPH to increase p-ERK1/2 in STZ-treated rats $(126 \pm 18 \% ; n=3)$, suggesting that this action of AMPH in hypoinsulinemic rats begins after only one administration of AMPH. Together, these data are consistent with the idea that $\mathrm{D}_{2}$ receptors are hyperactive in STZ-treated rats. Taking into consideration that ex vivo striatal preparations do not distinguish between presynaptic and postsynaptic DA receptors, we investigated a role for presynaptic $\mathrm{D}_{2}$ autoreceptors in mediating these effects of AMPH in STZ-treated rats with a history of AMPH injections. We performed HSCA experiments to measure AMPH-stimulated DA release in vivo after pharmacological inhibition of $\mathrm{D}_{2}$ receptors with RAC.

Repeated AMPH injections restore AMPH-induced DA efflux in striatum of STZ-treated rats

In these experiments, the same paradigm of repeated AMPH administration was used as described above, but two additional groups were studied. One group of rats received RAC and saline injections (RAC-SAL), and another received RAC and AMPH injections (RAC-AMPH), every other day for $8 \mathrm{~d}$. Replicating our published findings (Williams et al., 2007), in rats that received four injections every other day of SAL-SAL, the ability of intrastriatal AMPH (50 pmol) to elicit DA release was significantly decreased in STZ-treated rats $(0.28 \pm 0.04 \mu \mathrm{M})$ compared to control rats $\left(0.63 \pm 0.09 \mu \mathrm{M} ; t_{(16)}=3.374 ; p=0.004 ; n=9\right.$ per group) (Fig. 4A). Consistent with reduced plasma membrane DAT expression and/or activity, this was accompanied by a significant reduction in both the rate of DA release (SAL, $5.2 \pm 1.0$ $\mathrm{nm} / \mathrm{s}$ vs STZ, $\left.2.3 \pm 0.4 \mathrm{~nm} / \mathrm{s} ; t_{(16)}=2.673 ; p=0.017\right)$ and rate of DA clearance $\left(S A L, 2.2 \pm 0.6 \mathrm{~nm} / \mathrm{s}\right.$ vs STZ, $0.9 \pm 0.2 \mathrm{~nm} / \mathrm{s} ; t_{(16)}=$ 2.085; $p=0.050)$. Highlighted in Figure $4 B$ is the striking effect of four intraperitoneal injections every other day of AMPH (SALAMPH) to completely restore DA efflux in striatum following intrastriatal application of AMPH in STZ-treated rats. Summary data are shown in Figure 4E. This normalization occurred for all parameters, including release and clearance rates (data not shown). In control (euinsulinemic) rats, there was a tendency for repeated AMPH injections to enhance DA release, but this was not significant.

Most notably, rescue of DA efflux following intrastriatally applied AMPH could be completely blocked by administration of RAC, given $30 \mathrm{~min}$ before the every other day injection of AMPH (Fig. 4D, E, RAC-AMPH). Interestingly, in control rats that received only RAC (RAC-SAL), the effect of intrastriatally applied AMPH to stimulate DA release was blunted to the same magnitude as that following STZ treatment (Fig. 4C,E), further suggesting a pivotal role of the $\mathrm{D}_{2}$ receptor in modulating $\mathrm{AMPH}$ actions. STZ-treated rats receiving RAC-SAL did not show any greater blunting of AMPH-evoked release than in those that received SAL-SAL injections (Fig. 4C,E).

\section{Acute intrastriatal $D_{2}$ receptor blockade inhibits AMPH stimulated DA efflux}

Data presented thus far suggest that repeated injections of RAC can lead to sustained dampening of AMPH's ability to evoke DA release, even when RAC is fully metabolized and no longer exerting a direct action on $\mathrm{D}_{2}$ receptors (Sevak et al., 2007a). Others have reported that acute local injection of RAC into striatum can inhibit clearance of exogenous DA (Meiergerd et al., 1993; Cass and Gerhardt, 1994; Dickinson et al., 1999). Thus, the next experiments were designed to determine whether intrastriatal application of RAC inhibited AMPH-evoked DA release and whether this varied as a function of insulin status. In these experiments, baseline AMPH-stimulated DA release was measured, and then RAC ( $50 \mathrm{pmol}$ ) was pressure ejected into striatum. AMPH was applied intrastriatally again at 45 and 90 min following RAC. The results are illustrated in Figure 5. There was a significant main effect of both treatment $\left(F_{(2,12)}=5.32 ; p<0.05\right)$ and time $\left(F_{(2,12)}=12.05 ; p<0.001\right)$. In RAC-treated rats, AMPH-evoked DA release decreased with time. Bonferroni's post hoc analysis showed this effect to be greater in STZ-treated rats, compared to saline-treated control rats. Together, these data suggest that $\mathrm{D}_{2}$ receptor regulation of DAT is an important mediator of AMPH's ability to cause the release of DA.

\section{STZ treatment increases blood glucose and decreases body weight}

Tables 1 and 2 show the values for each treatment group used in HSCA studies, both before and after STZ or saline injection. Blood glucose and body weights did not vary among rats before 

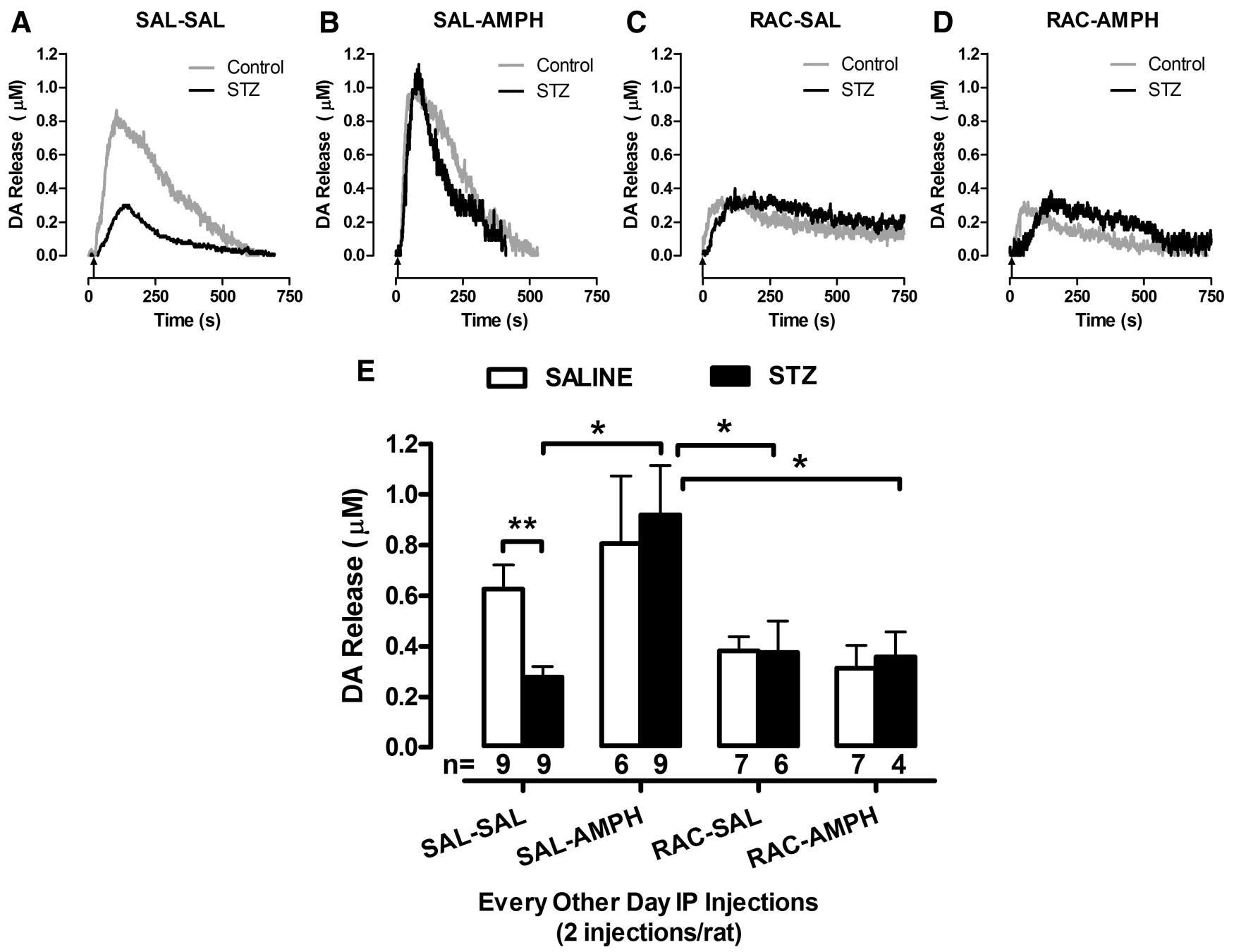

Figure 4. Repeated intraperitoneal AMPH injections restore the ability of intrastriatally applied AMPH to evoke DA efflux in STZ-treated rats by a $D_{2}$ receptor-dependent mechanism. $\boldsymbol{A}-\boldsymbol{D}$, Representative oxidation currents (converted to a micromolar concentration using a calibration factor determined in vitro). The time of intrastriatally applied AMPH is shown by the arrow. DA release following intrastriatal AMPH injection was dampened in STZ-treated (black trace) compared to control (saline-treated) rats (gray traces; $\boldsymbol{A}$ ), but rescued by four (every other day) intraperitoneal injections of systemically administered AMPH (B). Four injections (every other day) of raclopride (intraperitoneally) blunted the ability of intrastriatally applied AMPH to evoke DA release in control rats, but caused no further dampening of AMPH-evoked DA release in STZ-treated rats (C). However, raclopride did block the ability of repeated systemic AMPH injections to restore the ability of striatally applied AMPH to elicit DA release (D).E, Summary data for AMPH-stimulated DA release in saline-treated (controls; open bars) and STZ-treated rats (closed bars) treated repeatedly (every other day, intraperitoneal injections for $8 \mathrm{~d}$ ) with combinations of saline and saline (SAL-SAL), saline and amphetamine (1.78 mg/kg; SAL-AMPH), raclopride ( $0.056 \mathrm{mg} / \mathrm{kg})$ and saline (RAC-SAL), or raclopride $(0.056 \mathrm{mg} / \mathrm{kg}$ ) and amphetamine $(1.78 \mathrm{mg} / \mathrm{kg} ; \mathrm{RAC}-\mathrm{AMPH})$. Saline was injected in a volume of $1 \mathrm{ml} / \mathrm{kg}$. Data are expressed as the mean \pm SEM. of $4-9$ rats per condition; the sample size for each group is shown below each bar. ${ }^{*} p<0.05 ;{ }^{* *} p<0.01$ (two-way ANOVA with Bonferroni's multiple comparison test).

STZ or saline injection. At the conclusion of experiments, 15-17 $\mathrm{d}$ later, blood glucose was significantly elevated and body weight significantly decreased in STZ-treated rats. In contrast, blood glucose was unchanged and body weight increased in control (saline treated) rats. Blood glucose and body weight values did not vary as a function of the drug combination that rats received during the every other day for $8 \mathrm{~d}$ treatment regime. Thus, the following are pooled values across these groups. There was a significant main effect of treatment on blood glucose levels $\left(F_{(3,111)}=667.4 ; p<0.0001\right)$. Before injection of saline or STZ, blood glucose values were $93 \pm 3(n=29)$ and $95 \pm 5 \mathrm{mg} / \mathrm{dl}(n=$ 27), respectively. At the conclusion of experiments, blood glucose values were significantly elevated in STZ-treated rats $(494 \pm 14$ $\mathrm{mg} / \mathrm{dl} ; t=36.5 ; p<0.001)$, whereas they remained unchanged in control rats $(101 \pm 6 \mathrm{mg} / \mathrm{dl})$. There was also a significant main effect of treatment on body weight $\left(F_{(3,111)}=33.5 ; p<0.0001\right)$. Body weight did not differ between saline- and STZ-treated rats before treatment ( $355 \pm 4 \mathrm{~g}$ and $364 \pm 5 \mathrm{~g}$, respectively). At the completion of the study, STZ-treated rats weighed significantly less $(313 \pm 6 \mathrm{~g} ; t=7.33 ; p<0.001)$, and saline-treated rats significantly more ( $379 \pm 4 \mathrm{~g} ; t=3.55 ; p<0.01)$, compared to their starting weight. STZ-treated rats weighed less than their saline-treated counterpart at the conclusion of the study $(t=9.6$; $p<0.001$ ). Similarly, in fMRI studies, $18 \mathrm{~d}$ after STZ there was significant elevation in blood glucose levels and significant reduction in body weight relative to saline control in fMRI studies.

These data suggest that changes in the kinetics of AMPHinduced DA release and inhibition of uptake in STZ-treated rats are not due to hyperglycemia or differences in body weight. Blood glucose concentrations and body weights were the same across different groups of rats that received STZ, and which subsequently received different drug treatments that resulted in markedly varied abilities of AMPH to release DA. Therefore it is unlikely the hyperglycemia or body weight difference could ac- 


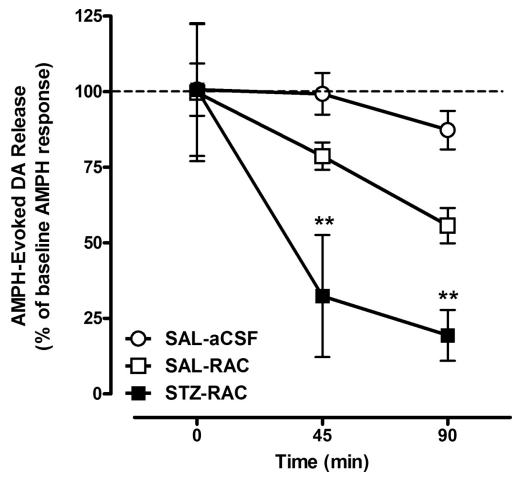

Figure 5. Intrastriatally applied raclopride blunts AMPH-stimulated DA release to a greater extent in STZ-treated rats than saline-treated control rats. Time 0 denotes baseline AMPHstimulated DA release in STZ-treated $(0.59 \pm 0.13 \mu \mathrm{m} ; n=3)$ and saline-treated control rats $(1.30 \pm 0.52 \mu \mathrm{m} ; n=3)$. Raclopride ( $50 \mathrm{pmol})$ or ACSF was pressure ejected into striatum, and then AMPH was applied intrastriatally again 45 and 90 min later. ${ }^{* *} p<0.01$ (two-way ANOVA with Bonferroni's multiple comparison test).

count for changes in the kinetics of intrastriatally applied AMPH-evoked DA release. Likewise, hyperglycemia does not significantly influence BOLD signals (Gruetter et al., 2000), suggesting that blunting of the AMPH-induced BOLD response in the DAT-dense striatum of insulin-depleted rats and its rescue by repeated systemic AMPH administration are not due to STZmediated metabolic abnormalities. Notably, the AMPH-induced BOLD response correlates with striatal extracellular DA levels (Chen et al., 1997, 1999) and, consequently, with DAT-mediated reverse transport of DA following acute AMPH. Together, these data further support the notion that normalization of the acute actions of AMPH by repeated systemic AMPH is unaffected by blood glucose and mediated by a PI3K-independent, ERK1/2dependent pathway.

\section{Acute intrastriatal inhibition of ERK1/2 slows DA clearance}

We have shown that AMPH-evoked DA release in striatum is blunted in STZ-treated rats and that this impairment can be rescued by repeated, systemic administration of AMPH, an effect that could be blocked by the $\mathrm{D}_{2}$ receptor antagonist, raclopride. $\mathrm{D}_{2}$ receptors are coupled to ERK signaling. We found that repeated systemic AMPH increased striatal ERK1/2 activity. To further study the putative link between ERK1/2 activity and DAT function, we determined the effect of local application of the ERK1/2 inhibitor SL327 into the striatum on clearance of exogenously applied DA. In these experiments, exogenous DA was pressure ejected into striatum until reproducible signals were obtained, and then SL327 was pressure ejected into striatum. Two minutes later, DA was again pressure ejected and at regular intervals thereafter until the signal returned to its pre-SL327 form. This approach is well established in our lab (Owens et al., 2005; Price et al., 2007) and those of others (Zahniser et al., 1999; Gulley et al., 2002) and affords a measure of DA clearance without an associated release component, as is the case with AMPH. We found that SL327 significantly slowed DA clearance, reflected by an increase in time course of the DA signal (Fig. 6) $\left(F_{(1,48)}=\right.$ $11.94 ; p<0.018$ ). Consistent with inhibition of DA uptake, DA signal amplitude also increased by $\sim 40 \%$ following SL327 (data not shown). Both signal amplitude and time course returned to predrug values 45 min following SL327 application. For rats treated with SL327, baseline (predrug) clearance time, defined as the time for DA to clear $80 \%$ from its peak signal amplitude, was $21 \pm 3 \mathrm{~s}$, and peak amplitude was $0.83 \pm 0.06 \mu \mathrm{M}(n=8)$.
Baseline clearance time and amplitude values for rats receiving vehicle did not differ and were $23 \pm 6 \mathrm{~s}$ and $0.79 \pm 0.03 \mu \mathrm{M}(n=$ $6)$, respectively. Vehicle had no significant effect on the clearance of exogenously applied DA (Fig. 6). These data are consistent with ERK1/2 signaling regulating DAT function in vivo.

\section{Insulin increases ERK1/2 activity, AMPH-evoked DA release, and DA clearance kinetics}

Our data suggest that both insulin and ERK1/2 signaling can regulate activity of DAT in terms of both the ability of AMPH to induce DA release and the efficiency with which DA can be cleared from extracellular fluid. We therefore sought to establish the relationship between the level of circulating insulin, ERK1/2 activity, and DAT function, as indexed by AMPH-evoked DA release and clearance of exogenously applied DA.

As shown in Figure 7, incubation of striatal synaptosomes prepared from untreated (euinsulinemic) rats with physiological concentrations of insulin (1 or $10 \mathrm{nM}$ ) produced significant increases in pERK1/2 [153 $\pm 9 \%$ and $254 \pm 28 \%$ for $1 \mathrm{nM} \mathrm{(10} \mathrm{min}$ incubation) and $10 \mathrm{nM}$ (5 min incubation), respectively].

To study the effect of increased circulating levels of insulin in the whole animal, we surgically implanted (subcutaneously) a group of rats with Linplant pellets that release $2 \mathrm{U}$ of insulin per day. Insulin delivered in this way has been shown to increase plasma insulin and decrease plasma glucose (Galipeau et al., 2002). In our experiments, blood glucose was significantly reduced in rats implanted with Linplant pellets (before, $113 \pm 4$ $\mathrm{mg} / \mathrm{dl} ; 7 \mathrm{~d}$ after implant, $99 \pm 4 \mathrm{mg} / \mathrm{dl} ; p<0.01$, paired $t$ test), whereas sham-operated rats showed no significant change in blood glucose levels (before, $110 \pm 5 \mathrm{mg} / \mathrm{dl} ; 7 \mathrm{~d}$ after sham implant, $122 \pm 9 \mathrm{mg} / \mathrm{dl} ; p=0.27)$. Using high-speed chronoamperometry to measure DA, we found that the ability of intrastriatally applied AMPH to evoke DA release was increased in hyperinsulinemic rats $(2.29 \pm 0.61 \mu \mathrm{M} ; n=8)$ compared to sham-operated rats $(0.78 \pm 0.36 \mu \mathrm{M} ; n=6)$, though this difference did not reach statistical significance ( $p=0.07$, Student's $t$ test).

To study the effect of circulating insulin on DA clearance, without an associated release component, we turned to exogenous application of DA into the striatum. A group of STZ-treated rats were included in these experiments for comparative purposes. Illustrated in Figure 8 is the striking association between DA clearance rate and insulin status. Hyperinsulimic (Linplant) rats cleared DA $\sim 1.5$-fold faster than control (euinsulinemic) rats. Replicating our previous findings (Owens et al., 2005), DA clearance rate was decreased approximately fivefold in hypoinsulinemic (STZ-treated) rats. These putative insulin-dependent changes in DA clearance rate were dependent on shifts in the maximal velocity $\left(V_{\max }\right)$ for DA clearance and not via shifts in the affinity of DAT for DA in vivo, denoted $K_{\mathrm{T}}$. $V_{\max }$ values were $436 \pm 169 \mathrm{~nm} / \mathrm{s}, 698 \pm 111 \mathrm{~nm} / \mathrm{s}$, and $85 \pm 16 \mathrm{nM} / \mathrm{s}$ for control and Linplant- and STZ-treated rats, respectively $\left(F_{(4,77)}=19.23\right.$; $p<0.001 ; n=5-7$ per group). $K_{\mathrm{T}}$ values were $6.6 \pm 1.0 \mu \mathrm{M}, 6.0 \pm$ $0.7 \mu \mathrm{M}$, and $4.3 \pm 1.1 \mu \mathrm{M}$, for control and Linplant- and STZtreated rats, respectively. Together, these data suggest that insulin signaling exerts tight control over DAT function in vivo. Moreover, they support the idea that insulin and repeated systemic administration of AMPH can act through ERK1/2 signaling to regulate DAT activity.

\section{Discussion}

A growing literature supports insulin regulation of DA neurotransmission as well as the progression and maintenance of drug dependence (Pandey, 1998; Carvelli et al., 2002; Garcia et al., 
Table 1. Blood glucose (milligrams per deciliter) values among STZ- and saline-treated rats receiving repeated injections of AMPH, raclopride, or saline

\begin{tabular}{lcccc}
\hline & SAL-SAL & SAL-AMPH & RAC-SAL & RAC-AMPH \\
\hline Baseline & & & & \\
$\quad$ Presaline & $95 \pm 5(9)$ & $101 \pm 5(6)$ & $83 \pm 5(7)$ & $93 \pm 6(7)$ \\
$\quad$ Pre-STZ & $97 \pm 5(9)$ & $98 \pm 9(8)$ & $82 \pm 6(6)$ & $105 \pm 25(4)$ \\
15-17 d post & & & & \\
$\quad$ Saline & $98 \pm 8(9)$ & $108 \pm 11(6)$ & $96 \pm 17(7)$ & $101 \pm 8(7)$ \\
STZ & $491 \pm 21^{*}(9)$ & $482 \pm 38^{*}(8)$ & $494 \pm 18^{*}(6)$ & $527 \pm 41^{*}(4)$ \\
\hline
\end{tabular}

Rats were injected once with either saline or STZ, and then $7 \mathrm{~d}$ later given two injections, once per day every other day for $8 \mathrm{~d}$. The first injection was given 30 min prior to the second. Injections comprised intraperitoneal administration of combinations of SAL, AMPH, and RAC. Number of rats is in parentheses.

${ }^{*} p<0.01$ from all saline counterpart and all baseline groups (two-way ANOVA with Bonferroni multiple comparison).

Table 2. Body weight (grams) values among STZ- and saline-treated rats receiving repeated injections of AMPH, raclopride, or saline

\begin{tabular}{lllll}
\hline & SAL-SAL & SAL-AMPH & RAC-SAL & \\
\hline Baseline & & & & \\
$\quad$ Presaline & $346 \pm 10(9)$ & $341 \pm 15(6)$ & $368 \pm 5(7)$ & $367 \pm 5(7)$ \\
$\quad$ Pre-STZ & $357 \pm 9(9)$ & $374 \pm 11(8)$ & $365 \pm 5(6)$ & $362 \pm 11(4)$ \\
$15-17$ d post & & & & $393 \pm 6(7)$ \\
$\quad$ Saline & $377 \pm 8(9)$ & $360 \pm 9(6)$ & $312 \pm 15^{*}(6)$ & $385 \pm 5(7)$ \\
STZ & $320 \pm 10^{*}(9)$ & $312 \pm 17^{*}(8)$ & $304 \pm 8^{*}(4)$ \\
\hline
\end{tabular}

Rats were injected once with either saline or STZ, and then $7 \mathrm{~d}$ later given two injections, once per day every other day for $8 \mathrm{~d}$. The first injection was given 30 min prior to the second. Injections comprised intraperitoneal administration of combinations of SAL, AMPH, and RAC. Number of rats is in parentheses.

${ }^{*} p<0.01$ from all saline counterpart and all baseline groups (two-way ANOVA with Bonferroni multiple comparison).

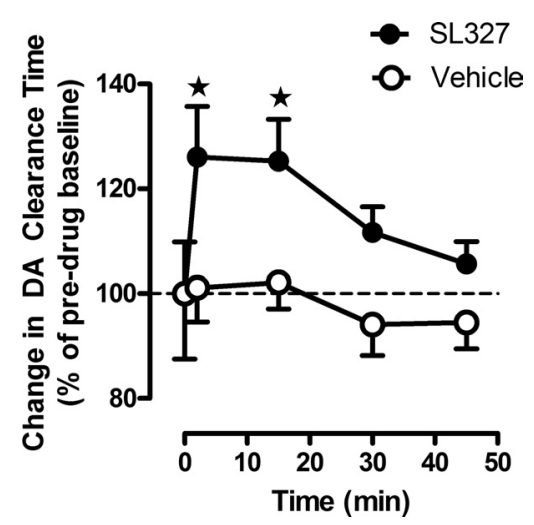

Figure 6. Intrastriatally applied SL327 inhibits DA clearance. DA was pressure ejected into striatum until a stable baseline was achieved (represented as time 0). The ERK1/2 inhibitor SL327 ( $30 \mathrm{nmol}$ ) or equivalent volume of vehicle (ACSF and 10\% DMSO) was pressure ejected into striatum and then DA was applied again 2, 15, 30, and 45 min later. ${ }^{*} p<0.018$ (two-way repeated measures ANOVA; SL327, $n=8$; vehicle, $n=6$ ).

2005; Izzo et al., 2002; Russo et al., 2007, Wei et al., 2007; Williams et al., 2007). One of the most striking findings is that lowered ambient levels of circulating insulin, as occur in diabetes or periods of fasting, produce dramatic decreases in DAT-mediated DA uptake as well as the ability of AMPH to elicit BOLD signals and cause DA release (Patterson et al., 1998; Owens et al., 2005; Sevak et al., 2007a; Williams et al., 2007) due to decreased plasma membrane expression of DAT (Williams et al., 2007). The effect of dampened insulin signaling on the kinetics of DA release and uptake can be fully restored by insulin replacement or other activators of PI3K/Akt signaling, which serve to restore plasma membrane expression of DAT (Williams et al., 2007). Here we find that repeated systemic injections of AMPH can restore the ability of intrastriatally applied AMPH to elicit DA release in hypoinsulinemic rats via $\mathrm{D}_{2}$-like receptor signaling as well as restore the BOLD response to a single acute injection of AMPH. These results reveal that PI3K/Akt-independent pathways can also rescue hypoinsulinemia-induced deficits in DAT function.

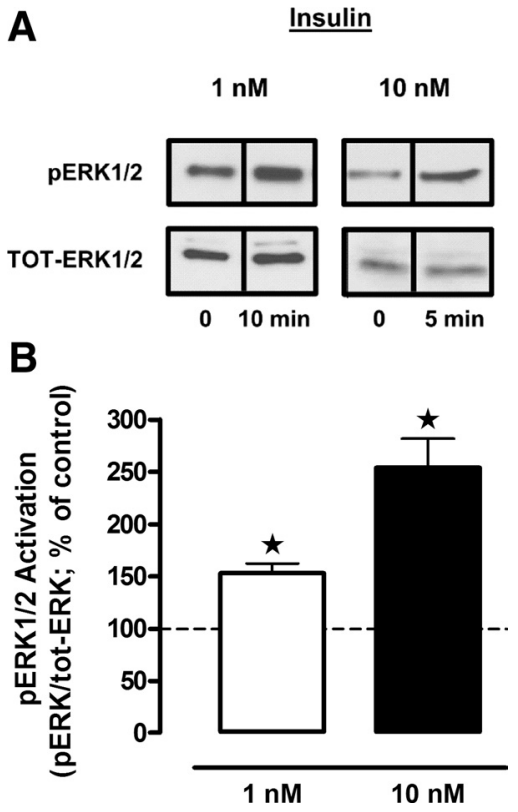

Figure 7. Insulin increases striatal ERK1/2 activity in rats. $A$, Representative immunoblots of p-ERK1/2 (top) and total ERK1/2 (bottom) obtained from striatal synaptosomes from untreated (euinsulinemic) rats, and incubated with either 1 or $10 \mathrm{~nm}$ insulin for 10 or $5 \mathrm{~min}$, respectively. $\boldsymbol{B}$, Summary data showing p-ERK1/2 normalized to total ERK1/2 and expressed as a percentage of respective controls (no insulin added). ${ }^{*} p<0.05$ (one-way ANOVA followed by Dunnett's test; $n=3$ per group).

Repeated activation of $\mathrm{D}_{2}$ receptors rescues STZ-induced deficits in AMPH-stimulated BOLD signals and DA release and increases ERK2 activity in striatum

The major novel finding of this study is that $\mathrm{D}_{2}$ receptor activation, via repeated (four, every other day) intraperitoneal injections of the indirect-acting agonist AMPH, fully restores the ability of a single acute dose of AMPH to elicit marked increases in striatal BOLD signals and the ability of intrastriatally applied AMPH to evoke DA release in hypoinsulinemic rats in vivo. We reported previously that STZ-treated rats show a blunted re- 


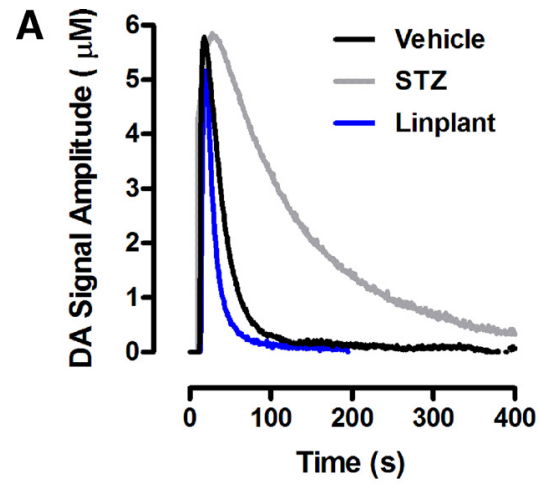

B

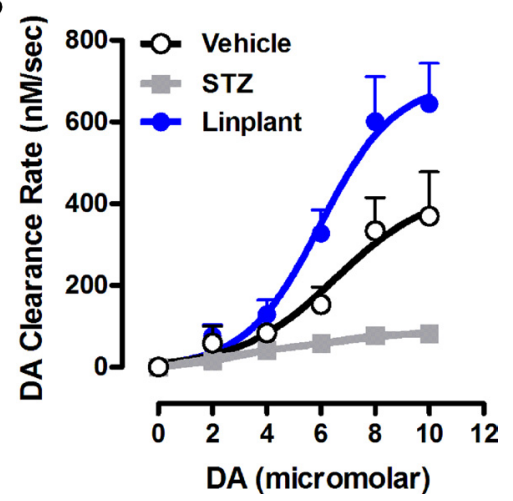

Figure 8. DA clearance rate is increased in hyperinsulinemic and decreased in hypoinsulinemic rats. $A$, Representative oxidation currents (converted to a micromolar concentration using a calibration factor determined in vitro), produced by pressure ejection of $40 \mathrm{pmol}$ of DA into the striatum of rats that, $7 \mathrm{~d}$ earlier, had received a Linplant insulin or sham pellet (subcutaneously) or an injection of $S T Z(50 \mathrm{mg} / \mathrm{kg}$, i.p.). Note the increased and decreased rate of DA clearance in Linplant-treated (hyperinsulinemic) and STZ-treated (hypoinsulinemic) rats, respectively. $\boldsymbol{B}$, Summary data where the rate of DA clearance is plotted as a function of increasing DA concentration. DA clearance rate did not differ between sham-operated and saline-injected control rats, and so the data were pooled. The curves represent sigmoid fits from which estimates of $V_{\max }$ and $K_{\mathrm{T}}$ were calculated. The fits were significantly different among treatments $(p<$ $0.001 ; n=5-7$ per group).

sponse to the locomotor stimulant effect of AMPH and that this too is normalized by repeated AMPH administration (Owens et al., 2005). Thus, consistent with restored effects of AMPH on behavior, here we show that so too are its neurochemical actions to stimulate DA release and induce BOLD signals. These effects occurred concurrently with strong activation of ERK1/2, consistent with findings that $\mathrm{D}_{2}$ receptor stimulation increases DAT function (Meiergerd et al., 1993; Cass and Gerhardt, 1994; Dickinson et al., 1999; Mayfield and Zahniser, 2001) and DAT cell surface expression, via phosphorylation and activation of ERK1/2 (p-ERK1/2) (Bolan et al., 2007; Lee et al. 2007). A role for $\mathrm{D}_{2}$-like receptors in mediating this effect of repeated systemic administration of AMPH was revealed by experiments showing that the $\mathrm{D}_{2} / \mathrm{D}_{3}$ antagonist RAC, given before systemic AMPH, completely blocked the rescue. RAC also has affinity for the $\mathrm{D}_{3}$ receptor, which can regulate DAT function and surface expression in cell systems in vitro (Zapata et al., 2007). However, $\mathrm{D}_{3}$ receptors are unlikely to mediate the effects observed here, since only very short exposure to $\mathrm{D}_{3}$ agonists $(1 \mathrm{~min}$ ) promoted increased cell surface DAT, whereas longer agonist exposure (30 min) decreased cell surface DAT expression. In sum, these data support the idea that internalization of DAT and subsequent reduction in DAT activity that occurs as a result of blunted insulin signaling at insulin receptors in STZ-treated rats (Williams et al., 2007) can be reversed by activation of $\mathrm{D}_{2}$ receptors by the indirect agonist AMPH. This activation likely triggers ERK1/2 signaling, which in turn promotes plasma membrane expression of DAT and increased DAT activity. However, future studies designed to block ERK1/2 signaling before repeated AMPH administration are needed before definitive conclusions can be made regarding the requirement for ERK1/2 signaling in the $\mathrm{D}_{2}$ receptor-dependent rescue of DAT function in hypoinsulinemic rats.

It is important to emphasize that all data were collected in the absence of drugs, 2 to $4 \mathrm{~d}$ after the last systemic drug administration. The 2 to $4 \mathrm{~d}$ "rest" period may be sufficient to bring any acutely elevated p-ERK1/2 levels back to baseline. As demonstrated by Shi and McGinty (2006), repeated administration of AMPH leads to elevated striatal p-ERK1/2 activity, but only after an additional "challenge" injection 15 min before the experiment (for review, see Shiflett and Balleine, 2011; Choe and Wang, 2002; Valjent et al., 2005); repeated AMPH injections did not elevate ERK activity without this challenge injection. This is consistent with our data (repeated AMPH in control rats) and suggests that STZ, and hence the diabetic state, might cause sensitization of the ERK pathway. A particularly novel finding, then, lies in the longlasting effects of repeated treatment with AMPH, RAC, or a combination thereof. The half-life for RAC is $<1 \mathrm{~h}$ in rats (Ericson et al., 1996); thus, at the time of HSCA recordings, RAC would be fully metabolized and eliminated. The half-life for AMPH is longer (5-9 h) (Kuhn and Schanberg, 1978). However, we showed previously that the ability of four intraperitoneal injections, every other day, of AMPH to restore clearance rates of exogenously applied DA into striatum of STZ-treated rats to normal persisted as long as $25 \mathrm{~d}$ after the last AMPH injection (the longest time point tested) (Owens et al., 2005), a time point well past that when AMPH might be present. It is most likely, therefore, that treatment-dependent restoration of the ability of intrastriatally applied AMPH to evoke DA release, and its prevention by RAC, results from persistent changes in DAT function that occur in response to repeated drug treatment, and not to acute effects and the lingering presence of drug.

\section{Intrastriatally applied raclopride blunting of} AMPH-stimulated DA release is greater in STZ-treated rats Other groups have demonstrated decreases in DA uptake following application of $\mathrm{D}_{2}$ receptor antagonists, and increases following $\mathrm{D}_{2}$ receptor agonists (Meiergerd et al., 1993; Cass and Gerhardt, 1994; Batchelor and Schenk, 1998; Mayfield and Zahniser, 2001). We extend these findings to show that intrastriatally applied RAC markedly attenuates the ability of subsequent intrastriatal application of AMPH (45 and 90 min later) to evoke DA release. This effect of RAC was apparent in both control and hypoinsulinemic rats; however, the relative magnitude of effect was significantly greater in hypoinsulinemic rats. These results are consistent with RAC decreasing expression and/or activity level of plasma membrane DAT and/or altering $\mathrm{D}_{2}$ receptor regulation of synaptic activity.

We showed that inhibition of basal ERK1/2 activity decreases DAT plasma membrane expression (Morón et al., 2003) and slows DA clearance from extracellular fluid in striatum (Fig. 6), raising the possibility that inhibition of ERK signaling via blockade of $\mathrm{D}_{2}$ receptors likely contributes to this effect of RAC to blunt the DA releasing activity of AMPH. Our data suggest that in STZ-treated rats, a greater fraction of AMPH-evoked DA release is RAC sensitive, and therefore that a greater fraction of DAT trafficking/activity is maintained by $\mathrm{D}_{2}$ receptor-ERK signaling in hypoinsulinemic conditions. Related to this, several studies 
show that diabetogenic agents increase binding of $\mathrm{D}_{2}$-like receptor ligands in striatum, which could be normalized to control levels by insulin replacement (Lozovskyet al. 1981; Trulson and Himmel 1983; Serri et al. 1985; Lim et al., 1994), supporting the idea that $\mathrm{D}_{2}$ receptor function may be enhanced in hypoinsulinemic rats. Further support comes from microdialysis studies showing that basal DA and AMPH-induced increases in DA were lower in diabetic than in normal rats (Murzi et al., 1996). This idea is further supported by our finding that repeated AMPH significantly enhanced the ability of intrastriatally applied AMPH to evoke DA release only in STZ-treated rats. In control rats, repeated AMPH did not further increase the ability of intrastriatal AMPH to elicit DA release, suggesting that $\mathrm{D}_{2}$ receptor sensitivity to the indirect-acting agonist is not enhanced in control (euinsulinemic) rats.

\section{Implications}

While insulin is well known for its important role in regulating energy homeostasis, it is now recognized to be an important regulator of monoaminergic neurotransmission (Fig. 8) (Figlewicz and Benoit, 2009; Daws et al., 2011; Niswender et al., 2011). We and others have shown that conditions that dampen insulin signaling, such as diabetes, food restriction, or fasting, dramatically impair the ability of DAT to clear DA from extracellular fluid in brain areas subserving reward, as well as motivated and learned behaviors including drug- and food-seeking activities (Figlewicz et al., 2007; Palmiter, 2007, 2008). Furthermore and importantly, in the context of drug abuse, impaired insulin signaling blunts the ability of AMPH to evoke DA release. We found these effects of hypoinsulinemia to be due to PI3K/Akt mediated decreases in plasma membrane expression of DAT. Here we show that we can override the effect of hypoinsulinemia to blunt the actions of AMPH by repeated stimulation of $\mathrm{D}_{2}$-like receptors, an effect likely mediated by stimulation of ERK2 signaling, which restores DAT to the plasma membrane.

DA is well known to play a major role in the regulation of cognition, food intake, and motor and behavioral function, and abnormalities in DA neurotransmission are implicated in a number of psychiatric and neurological disorders, including drug addiction, schizophrenia, and Parkinson's disease. Given that DAT is a major regulator of ambient DA levels, its dysregulation by abnormal insulin levels could have profound, potentially detrimental effects. With the growing incidence of diabetes, obesity, and eating disorders (including anorexia), all of which are associated with disrupted insulin signaling, understanding the mechanism by which insulin regulates DAT and, importantly, mechanisms that can override these effects, will be critical for the design of therapeutics to target DA-related pathologies.

\section{References}

Batchelor M, Schenk JO (1998) Protein kinase A activity may kinetically upregulate the striatal transporter for dopamine. J Neurosci 18:10304-10309.

Bolan EA, Kivell B, Jaligam V, Oz M, Jayanthi LD, Han Y, Sen N, Urizar E, Gomes I, Devi LA, Ramamoorthy S, Javitch JA, Zapata A, Shippenberg TS (2007) D2 receptors regulate dopamine transporter function via an extracellular signal-regulated kinases 1 and 2-dependent and phosphoinositide 3 kinase-independent mechanism. Mol Pharmacol 71:1222-1232.

Callaghan PD, Irvine RJ, Daws LC (2005) Differences in the in vivo dynamics of neurotransmitter release and serotonin uptake after acute paramethoxyamphetamine and 3,4-methylenedioxymethamphetamine revealed by chronoamperometry. Neurochem Int 47:350-361.

Carr KD, Kim G-Y, Cabeza de Vaca S (2000) Hypoinsulinemia may mediate the lowering of self-administration thresholds by food restriction and streptozotocin-induced diabetes. Brain Res 863:160-168.
Carvelli L, Morón JA, Kahlig KM, Ferrer JV, Sen N, Lechleiter JD, LeebLunberg LM, Merrill G, Lafer EM, Ballou LM, Shippenberg TS, Javitch JA, Lin RZ, Galli A (2002) PI3-kinase regulation of dopamine uptake. J Neurochem 81:859-869.

Cass WA, Gerhardt GA (1994) Direct in vivo evidence that D2 dopamine receptors can modulate dopamine uptake. Neurosci Lett 185:52-55.

Chen YC, Galpern WR, Brownell AL, Matthews RT, Bogdanov M, Isacson O, Keltner JR, Beal MF, Rosen BR, Jenkins BG (1997) Detection of dopaminergic neurotransmitter activity using pharmacologic MRI: correlation with PET, microdialysis, and behavioral data. Magn Reson Med 38:389-398.

Chen YI, Brownell AL, Galpern W, Isacson O, Bogdanov M, Beal MF, Livni E, Rosen BR, Jenkins BG (1999) Detection of dopaminergic cell loss and neural transplantation using pharmacological MRI, PET and behavioral assessment. Neuroreport 10:2881-2886.

Choe ES, Wang JQ (2002) CaMKII regulates amphetamine-induced ERK1/2 phophorylation in striatal neurons. Neuroreport 13:1013-1016.

Clausing P, Gough B, Holson RR, Slikker W, Bowyer JF (1995) Amphetamine levels in brain microdialysate, caudate/putamen, substantia nigra and plasma after dosage that produces either behavioral or neurotoxic effects. J Pharmacol Exp Ther 274:614-621.

Daws LC, Avison MJ, Robertson SD, Niswender KD, Galli A, Saunders C (2011) Insulin signaling and addiction. Neuropharmacology 61:11231128.

Dickinson SD, Sabeti J, Larson GA, Giardina K, Rubinstein M, Kelly MA, Grandy DK, Low MJ, Gerhardt GA, Zahniser NR (1999) Dopamine D2 receptor-deficient mice exhibit decreased dopamine transporter function but no changes in dopamine release in dorsal striatum. J Neurochem 72:148-156.

Ericson H, Radesater AC, Servin E, Magnusson O, Mohringe B (1996) Effects of intermittent and continuous subchronic administration of raclopride on motor activity, dopamine turnover and receptor occupancy in the rat. Pharmacol Toxicol 79:277-286.

Figlewicz DP, Benoit SC (2009) Insulin, leptin, and food reward: update 2008. Am J Physiol Regul Integr Comp Physiol 296:R9-R19.

Figlewicz DP, MacDonald NA, Sipols AJ (2007) Modulation of food reward by adiposity signals. Physiol Behav 91:473-478.

Galipeau DM, Yao L, McNeill JH (2002) Relationship among hyperinsulinemia, insulin resistance, and hypertension is dependent on sex. Am J Physiol Heart Circ Physiol 283:562-567.

Garcia BG, Wei Y, Morón JA, Lin RZ, Javitch JA, Galli A (2005) Akt is essential for insulin modulation of amphetamine-induced human dopamine transporter cell-surface redistribution. Mol Pharmacol 68:102-109.

Gruetter R, Ugurbil K, Seaquist ER (2000) Effect of acute hyperglycemia on visual cortical activation as measured by functional MRI. J Neurosci Res 62:279-285.

Gulley JM, Doolen S, Zahniser NR (2002) Brief, repeated exposure to substrates down-regulates dopamine transporter function in Xenopus oocytes in vitro and rat dorsal striatum in vivo. J Neurochem 83:400-411.

Izzo E, Martin-Fardon R, Koob GF, Weiss F, Sanna PP (2002) Neural plasticity and addiction: PI3-kinase and cocaine behavioral sensitization. Nat Neurosci 5:1263-1264.

Kuhn CM, Schanberg SM (1978) Metabolism of amphetamine after acute and chronic administration to the rat. J Pharmacol Exp Ther 207:544-554

Lee FJ, Pei L, Moszczynska A, Vukusic B, Fletcher PJ, Liu F (2007) Dopamine transporter cell surface localization facilitated by a direct interaction with the dopamine D2 receptor. EMBO J 26:2127-2136.

Lim DK, Lee KM, Ho IK (1994) Changes in central dopaminergic systems in the streptozotocin-induced diabetic rats. Arch Pharm Res 17:398-404.

Lozovsky D, Saller CF, Kopin IJ (1981) Dopamine receptor binding is increased in diabetic rats. Science 214:1031-1033.

Mayfield RD, Zahniser NR (2001) Dopamine D2 receptor regulation of the dopamine transporter expressed in Xenopus laevis oocytes is voltageindependent. Mol Pharmacol 59:113-121.

Meiergerd SM, Patterson TA, Schenk JO (1993) D2 receptors may modulate the function of the striatal transporter for dopamine: kinetic evidence from studies in vitro and in vivo. J Neurochem 61:764-767.

Morón JA, Zakharova I, Ferrer JV, Merrill GA, Hope B, Lafer EM, Lin ZC, Wang JB, Javitch JA, Galli A, Shippenberg TS (2003) Mitogen-activated protein kinase regulates dopamine transporter surface expression and dopamine transport capacity. J Neurosci 23:8480-8488. 
Murzi E, Contreras Q, Teneud L, Valecillos B, Parada MA, De Parada MP, Hernandez L (1996) Diabetes decreases limbic extracellular dopamine in rats. Neurosci Lett 202:141-144.

Niswender KD, Daws LC, Avison MJ, Galli A (2011) Insulin regulation of monoamine signaling: pathway to obesity. Neuropsychopharmacology 36:359-360.

Owens WA, Sevak RJ, Galici R, Chang X, Javors MA, Galli A, France CP, Daws LC (2005) Deficits in dopamine clearance and locomotion in hypoinsulinemic rats unmask novel modulation of dopamine transporters by amphetamine. J Neurochem 94:1402-1410.

Palmiter RD (2007) Is dopamine a physiologically relevant mediator of feeding behavior? Trends Neurosci 30:375-381.

Palmiter RD (2008) Dopamine signaling in the dorsal striatum is essential for motivated behaviors: lessons from dopamine-deficient mice. Ann N Y Acad Sci 1129:35-46.

Pandey SC (1998) Neuronal signaling systems and ethanol dependence. Mol Neurobiol 17:1-15.

Patterson TA, Brot MD, Zavosh A, Schenk JO, Szot P, Figlewicz DP (1998) Food deprivation decreases mRNA and activity of the rat dopamine transporter. Neuroendocrinology 68:11-20.

Paxinos G, Watson C (1998) The rat brain in stereotaxic coordinates New York: Academic.

Price DA, Owens WA, Gould GG, Frazer A, Roberts JL, Daws LC, Guiffrida A (2007) CB1-independent inhibition of dopamine transporter activity by cannabinoids in mouse dorsal striatum. J Neurochem 101:389-396.

Russo SJ, Bolanos CA, Theobald DE, DeCarolis NA, Renthal W, Kumar A, Winstanley CA, Renthal NE, Wiley MD, Self DW, Russell DS, Neve RL, Eisch AJ, Nestler EJ (2007) IRS2-Akt pathway in midbrain dopamine neurons regulates behavioral and cellular responses to opiates. Nat Neurosci 10:93-99.

Serri O, Renier G, Somma M (1985) Effects of alloxan-induced diabetes on dopaminergic receptors in rat striatum and anterior pituitary. Horm Res 21:95-101.

Sevak RJ, Owens WA, Koek W, Galli A, Daws LC, France CP (2007a) Evidence for D2 receptor mediation of amphetamine-induced normalization of locomotion and dopamine transporter function in hypoinsulinemic rats. J Neurochem 101:151-159.

Sevak RJ, Koek W, Galli A, France CP (2007b) Insulin replacement restores the behavioral effects of quinpirole and raclopride in streptozotocintreated rats. J Pharmacol Exp Ther 320:1216-1223.

Shi X, McGinty JF (2006) Extracellular signal-regulated mitogen-activated protein kinase inhibitors decrease amphetamine-induced behavior and neuropeptide gene expression in the striatum. Neuroscience 138:1289 1298.

Shiflett MW, Balleine BW (2011) Contributions of ERK signaling in the striatum to instrumental learning and performance. Behav Brain Res 218:240-247.

Szkudelski T (2001) The mechanism of alloxan and streptozotocin action in B cells of the rat pancreas. Physiol Res 50:537-546.

Trulson ME, Himmel CD (1983) Decreased brain dopamine synthesis rate and increased $\left[{ }^{3} \mathrm{H}\right]$ spiroperidol binding in streptozotocin-diabetic rats. J Neurochem 40:1456-1459.

Valjent E, Pascoli V, Svenningsson P, Paul S, Enslen H, Corvol JC, Stipanovich A, Caboche J, Lombroso PJ, Nairn AC, Greengard P, Hervé D, Girault JS (2005) Regulation of a protein phosphatase cascade allows convergent dopamine and glutamate signals to activate ERK in the striatum. Proc Natl Acad Sci U S A 102:491-496.

Wei Y, Williams JM, Dipace C, Sung U, Javitch JA, et al (2007) Dopamine transporter activity mediates amphetamine-induced inhibition of Akt through a Ca2+/calmodulin-dependent kinase II-dependent mechanism. Mol Pharmacol 71:835-842.

Williams JM, Owens WA, Turner GH, Saunders C, Dipace C, Blakely RD, France CP, Gore JC, Daws LC, Avison MJ, Galli A (2007) Hypoinsulinemia regulates amphetamine-induced reverse transport of dopamine. PLoS Biol 5:2369-2378.

Williams JM, Milatovic D, Gore JC, Aschner M, Avison MJ (2010) Chronic exposure to manganese alters brain responses to amphetamine: a pharmacological magnetic resonance imaging study. Toxicol Sci 114:310-322.

Zahniser NR, Larson GA, Gerhardt GA (1999) In vivo dopamine clearance rate in rat striatum: regulation by extracellular dopamine concentration and dopamine transporter inhibitors. J Pharmacol Exp Ther 289:266277.

Zapata A, Kivell B, Han Y, Javitch JA, Bolan EA, Kuraguntla D, Jaligam V, Oz M, Jayanthi LD, Samuvel DJ, Ramamoorthy S, Shippenberg TS (2007) Regulation of dopamine transporter function and cell surface expression by $\mathrm{D}_{3}$ dopamine receptors. J Biol Chem 282:35842-35854. 